\title{
Performance Study of Novel Accelerationenhanced Filters in the Prediction of Normal and Irregular Respiration Motion
}

\author{
K. Huang \\ Thomas Jefferson University and Hospitals \\ I. Buzurovic \\ Thomas Jefferson University and Hospitals \\ M. Werner-Wasik \\ Thomas Jefferson University and Hospitals \\ T. Biswas \\ Thomas Jefferson University and Hospitals
}

A. Dicker

Thomas Jefferson University and Hospitals. Follow this and additional works at: https://jdc.jefferson.edu/bodinejournal

Part of the Oncology Commons

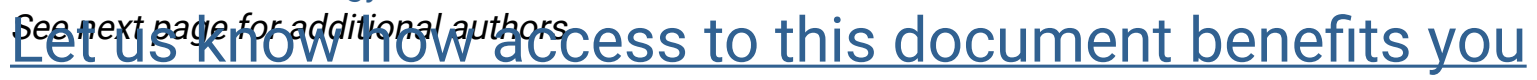

\section{Recommended Citation}

Huang, K.; Buzurovic, I.; Werner-Wasik, M.; Biswas, T.; Dicker, A.; Galvin, J.; Yu, Y.; and Podder, T. (2010) "Performance Study of Novel Accelerationenhanced Filters in the Prediction of Normal and Irregular Respiration Motion," Bodine Journal: Vol. 3 : Iss. 1 , Article 12.

DOI: https://doi.org/10.29046/TBJ.003.1.011

Available at: https://jdc.jefferson.edu/bodinejournal/vol3/iss1/12

This Article is brought to you for free and open access by the Jefferson Digital Commons. The Jefferson Digital Commons is a service of Thomas Jefferson University's Center for Teaching and Learning (CTL). The Commons is a showcase for Jefferson books and journals, peer-reviewed scholarly publications, unique historical collections from the University archives, and teaching tools. The Jefferson Digital Commons allows researchers and interested readers anywhere in the world to learn about and keep up to date with Jefferson scholarship. This article has been accepted for inclusion in Bodine Journal by an authorized administrator of the Jefferson Digital Commons. For more information, please contact: JeffersonDigitalCommons@jefferson.edu. 


\section{Performance Study of Novel Accelerationenhanced Filters in the Prediction of Normal and Irregular Respiration Motion}

\section{Authors}

K. Huang, I. Buzurovic, M. Werner-Wasik, T. Biswas, A. Dicker, J. Galvin, Y. Yu, and T. Podder 


\title{
Performance Study of Novel Acceleration- enhanced Filters in the Prediction of Normal and Irregular Respiration Motion
}

\author{
Huang, K., Buzurovic, I., Werner-Wasik, M., Biswas, T., Dicker, A., Galvin, J., Yu, Y., Podder, T. \\ Department of Radiation Oncology, Thomas Jefferson University and Hospitals, Philadelphia, PA
}

\section{Purpose}

To study the performance of the novel acceleration-enhanced (AE) filters in the prediction of normal and irregular respiration motion and compare them with those of traditional adaptive normalized least mean squares (nLMS) and adaptive neuron network (ANN) filters. This facilitates the real-time tumor tracking and dynamic delivery of radiation dose to the tumor.

\section{Method and Materials}

Respiration signals are collected from volunteers under IRB-approved protocol by respiration sensor, which is able to sense the expansion and contraction of the rib cage. One-dimensional respiration signal is used in this work for the evaluation of the performances from different prediction filters. The respiration signals are captured at a frequency of $256 \mathrm{~Hz}$ and sampled at $32 \mathrm{~Hz}$. The prediction performances of the filters in the prediction of normal and irregular respiration are compared, including adaptive nLMS and adaptive ANN filters, as well as their AE versions, which use the accelerations derived from the predicted velocities for further corrections to the predicted positions.

\section{Results}

The adaptive ANN filter performs better than the adaptive nLMS filter in the prediction of normal respiration whereas the latter excels in predicting irregular respiration signals. The implementation of AE method prompts the performances of the traditional filters. For example, with a prediction time fixed at $250 \mathrm{~ms}$, the ANN and nLMS filters gave percentage root mean square (RMS) prediction errors of $3.51 \%$ and $4.25 \%$ for normal respiration, and $8.85 \%$ and $6.17 \%$ for irregular respiration, respectively. AE-ANN filter gives a percentage RMS error of $3.45 \%$ in normal respiration prediction and AE-nLMS has a $5.87 \%$ RMS error in irregular respiration prediction.

\section{Conclusion}

The acceleration-enhanced method is able to improve the performance of the traditional filters. The AE-ANN and AE-nLMS filter give the minimum error in the prediction of the normal and irregular respiration, respectively.

Supported by Elekta, Ltd. 